\title{
Study of tribological properties of moulds obtained by stereolithography
}

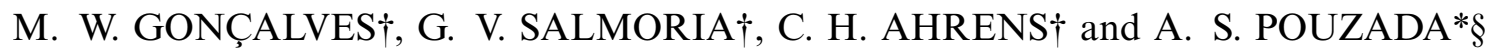 \\ $\dagger$ †epartamento de Engenharia Mecânica, Universidade Federal de Santa Catarina, Florianópolis, Brazil \\ §Institute for Polymers and Composites-Department of Polymer Engineering, University of Minho, 4800-058 Guimarães, \\ Portugal
}

\begin{abstract}
Stereolithography (SL) is a process that allows the rapid manufacturing of high-accuracy rapid tools using an ultraviolet laser beam to polymerize a liquid resin, layer-by-layer. In this work, the friction properties of commercial SL resins in contact with several thermoplastics were assessed. Friction experiments were done with plastics overmoulded onto moulding blocks made from SL resins. It was observed that polymers with Hildebrand solubility parameters close to the resins showed adhesion characteristics that were not observed in polymers with values of this parameter further apart.
\end{abstract}

Keywords: Stereolithography; Hybrid moulds; Thermoplastics; Friction; Injection moulding

\section{Introduction}

The use of injection moulds for production of small series of products or for prototype runs gave rise to the concept of hybrid moulds: tools consisting of a standard steel structure and moulding blocks produced by fast forming methods and using alternative materials. Today, rapid tools using moulding blocks manufactured by stereolithography (SL) are suitable for production of short runs of parts or prototypes, without resorting to a conventional metal mould (e.g. Cedorege et al. 1999, Colton and Lebaut 2000, Hopkinson and Dickens 1999, Ribeiro et al. 2004). $\mathrm{SL}$ is a process that allows the rapid manufacturing of highaccuracy rapid tools using an ultraviolet (UV) laser beam to polymerize a liquid resin, layer-by-layer (Jacobs 1996).

The properties of the SL resins are very different from the metals. Therefore, when the production of a given number of parts using SL moulding blocks is considered, the knowledge of the mechanical and thermal properties of the SL resins and those of the thermoplastics to be injected are very important for the success of the production. Consequently the use of hybrid moulds with SL moulding blocks brings about strength issues associated to the lower resistance of the SL resins (e.g. Palmer and Colton 2000, Salmoria et al. 2005).

During injection moulding, the thermoplastic tends to replicate the mould surface (Menges 1981). During the cooling of the moulding, the roughness of the polymer and the mould surfaces, the shrinkage undergone by the polymer and the adhesion between the two materials, originates a resistance to the ejection that must be overcome for removing the moulding from the mould.

The friction properties of pairs of materials are usually represented by the coefficient of friction, $\mu$. The coefficient of friction is defined (e.g in the ASTM G40 test standard) as

$$
\mu=F / N
$$

where

$$
\begin{aligned}
& F \text { is friction force } \\
& N \text { is normal contact force }
\end{aligned}
$$

This standard also defines the coefficient of static friction, $\mu_{\mathrm{s}}$, corresponding to the maximum force to be overcome to initiate macroscopic motion between two bodies.

*Corresponding author. Email: asp@dep.uminho.pt 

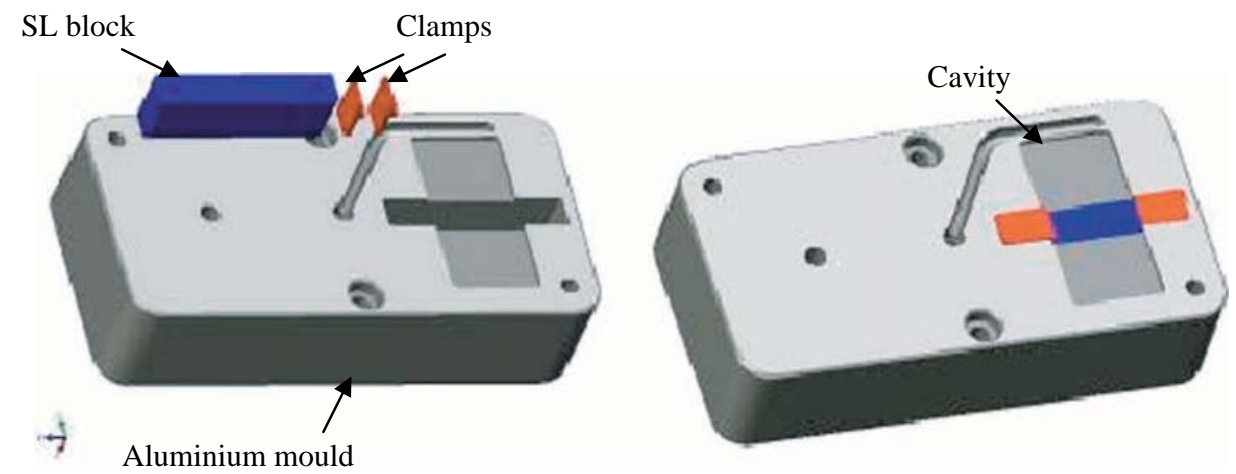

Figure 1. Illustration of the cavity of the aluminium mould for the overmoulding of the thermoplastic onto the SL resin blocks.

In conventional injection moulding, where metals are used to build the mould, the origin of the friction force during ejection results mainly from the roughness of the surfaces and the shrinkage undergone by the thermoplastic. However in hybrid moulds using polymeric moulding blocks, as those produced by SL the contact between polymer-polymer, principally at high temperatures, and the chemical adhesion can be relevant (Lavielle 1991, Fourche 1995a and Fourche 1995b).

In this work, the friction properties of moulded thermoplastics (PP, ABS, PET and PA 6.6) in contact with moulding blocks made from SL resins (Ren Shape 5260 and Somos 7110) were assessed. The surface topography of the SL moulding blocks throughout the process of injection moulding was evaluated using light microscopy and a contactless laser technique.

\section{Experimental}

\subsection{SL resin moulding blocks}

Eight moulding blocks were produced in Huntsman SL RenShape 5260 resin using the 3D Systems SLA 250 A SL equipment. These parts were post-cured in a conventional oven during $15 \mathrm{~min}$ at $125^{\circ} \mathrm{C}$. Another eight moulding blocks were machined from a slab of Somos 7110 SL resin that was previously photopolymerized for $5 \mathrm{~h}$ in a UV chamber and post-cured in a conventional oven during $30 \mathrm{~min}$ at $125^{\circ} \mathrm{C}$.

Table 1. Moulding conditions.

\begin{tabular}{lccccc}
\hline & $\begin{array}{c}\text { Injection } \\
\text { time }(\mathrm{s})\end{array}$ & $\begin{array}{c}\text { Injection } \\
\text { pressure } \\
\left({ }^{\circ} \mathrm{C}\right)\end{array}$ & $\begin{array}{c}\text { Holding } \\
\text { pressure } \\
(\mathrm{MPa})\end{array}$ & $\begin{array}{c}\text { Holding } \\
\text { time }(\mathrm{s})\end{array}$ \\
\hline PP & 50 & $190-250$ & 50 & 20 & 20 \\
ABS & 50 & $200-260$ & 70 & 50 & 20 \\
PET & 70 & $250-280$ & 90 & 30 & 10 \\
PA 6.6 & 60 & $250-276$ & 90 & 25 & 10 \\
\hline
\end{tabular}

\subsection{Injection moulding}

An aluminium mould was developed for producing the plastics samples to be tested for determination of the coefficient of friction. This mould allowed the overmoulding of the thermoplastics onto the SL resin blocks as illustrated in figure 1. Two clamps were assembled together with the SL blocks for keeping the injected material in contact only with the testing part of the SL block. Furthermore these clamps help to keep the mouldings and the SL blocks together until the friction test is performed.

The overmoulding of the thermoplastics was done in a Klöckner Ferromatik FM 20 injection moulding machine of $200 \mathrm{kN}$ clamping force.

Several materials were used for moulding: polypropylene (PP) HE 125MO from Borealis S.A., acrylo-nitrile-butadiene (ABS) Cycolac G360 from GE Plastics, poly(therephtalate ethylene) (PET) S86G from Selenis, and polyamide 6.6 (PA 6.6) Technyl A216 from Rhodia

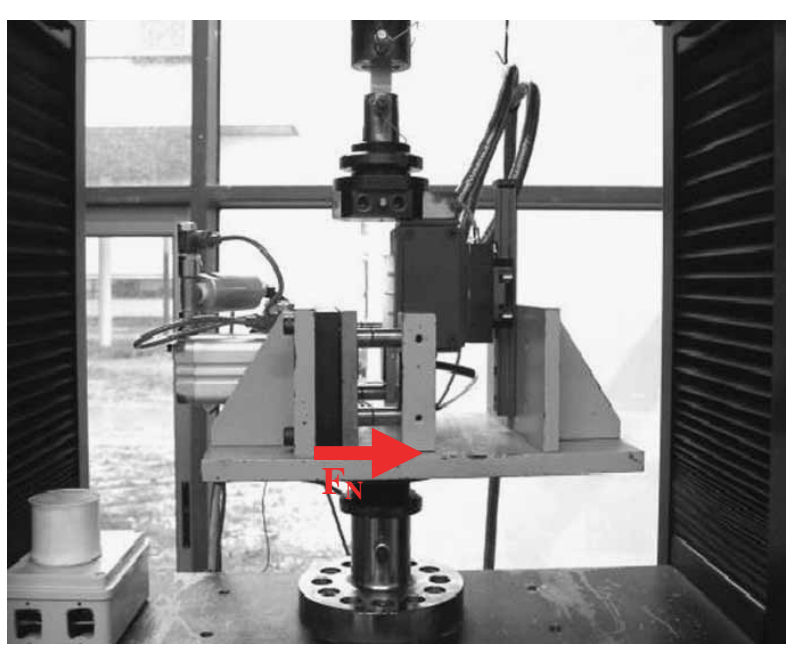

Figure 2. Mould friction equipment. 


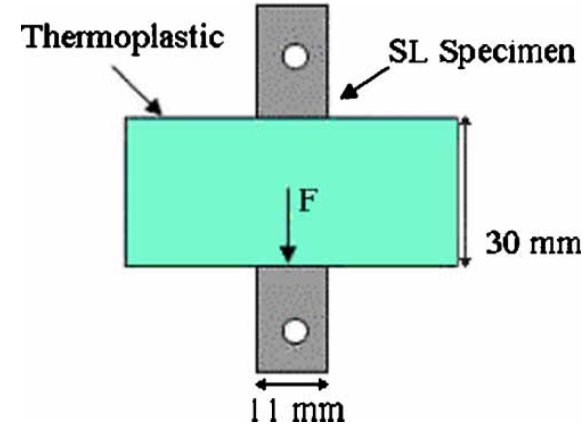

Figure 3. Friction test illustration.

Engineering Plastics. The main injection moulding parameters are shown in table 1.

Periodically, every five moulding cycles, the pair (SL block + moulding) was carefully placed in the prototype Mouldfriction equipment (Ferreira et al. 2002) which was previously installed in an Instron 4505 universal testing machine. This prototype was developed for determining the coefficient of friction in as-moulding conditions (Pouzada et al. 2006). The friction tests were performed at room temperature. The coefficient of friction between the SL blocks and the mouldings were determined as illustrated in figures 2 and 3 using a normal contact force of $275 \mathrm{~N}$.

For each moulded thermoplastic two blocks from each of the two SL resins were used. For each processing condition and SL block material, 21 mouldings were produced.

\subsection{Microscopy analysis and roughness analysis}

The evaluation of the surface topography of the SL blocks along the experimental procedure (moulding and friction tests) was made using optical microscopy and contactless laser roughness measurement. The surface analysis was made with an Olympus BH 12 optical microscope. For the measurement of the surface roughness the MICROTOP.06 MFC prototype equipment, which is based on the method of the active triangulation with oblique laser incidence and sample synchronized scanning (Costa 1996), was used.

\section{Results}

\subsection{Polypropylene}

The coefficient of friction before overmoulding for both SL resins in contact with every thermoplastics was approximately 0.15 , corresponding to a friction force of $42.2 \mathrm{~N}$. After overmoulding, the coefficient of friction tends to increase. In the case of PP and SL Somos 7110 blocks the coefficient of friction raised to $0.27(\mathrm{Fa}=73.7 \mathrm{~N})$, corresponding to an increase of $80 \%$ after 15 injection moulding cycles. At this stage the coefficient of friction stabilized at this value. The friction behaviour of PP in contact with the SL Huntsman 5260 surface was similar. In this case, the maximum coefficient of friction was reached after 5 injection cycles $(\mu=0.23 / \mathrm{Fa}=63 \mathrm{~N})$ as depicted in figure 4.

No relevant changes were observed in the SL block surfaces before and after the experiments (figure 5). However the apparent and medium roughness ( $\mathrm{Ra}$ and Rq respectively) showed small changes after overmoulding. The Ra values increase from 0.36 to 0.45 in the SL Somos 7110 resin but curiously a decrease from 1.08 to 0.64 in the SL Huntsman 5260 resin (table 2) This suggests that the blocks may had suffered plastic deformation during the moulding and friction tests.

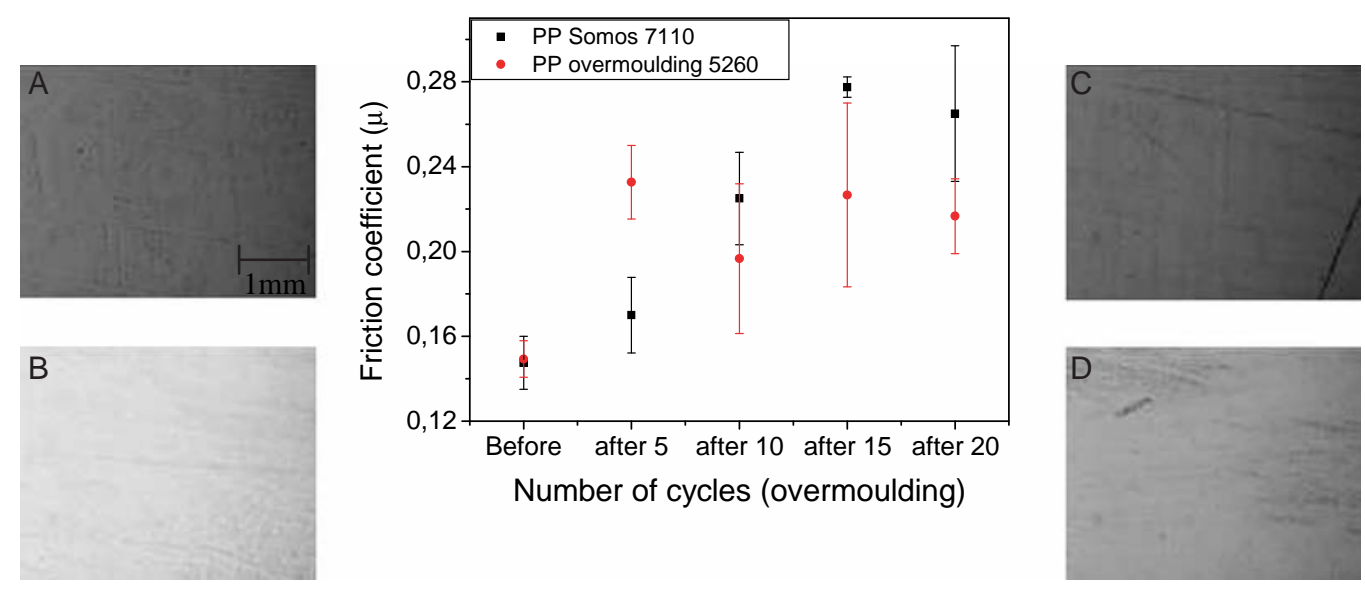

Figure 4. Coefficient of friction between SL blocks and PP. (a) Somos 7110 surface before PP overmoulding; (b) Huntsman 5260 surface before PP overmoulding; (c) Somos 7110 surface after PP overmoulding (d) Huntsman 5260 surface after PP overmoulding. 

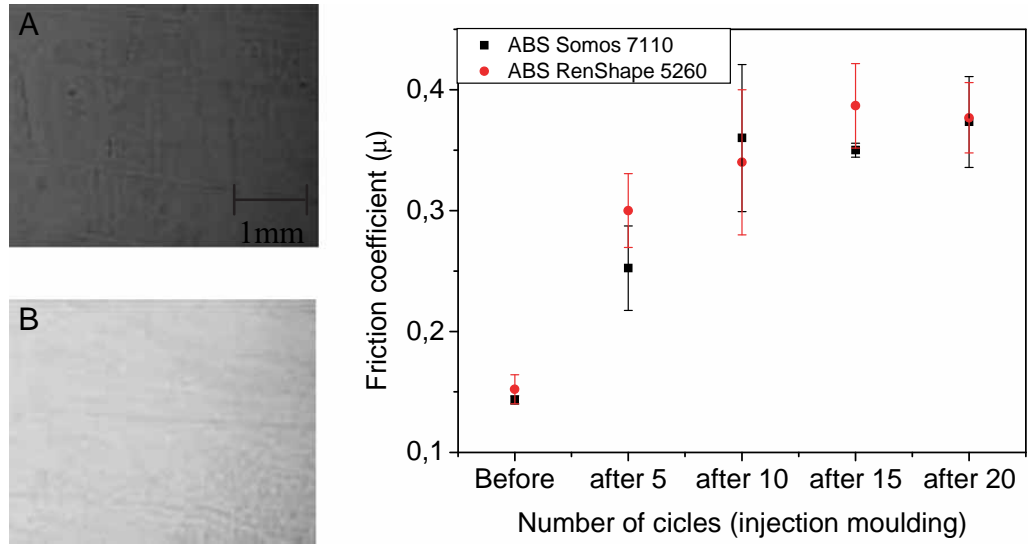

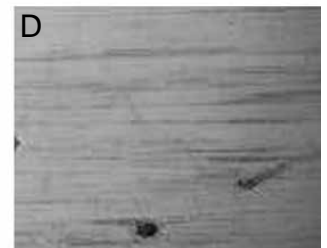

Figure 5. Coefficient of friction between SL blocks and ABS: (a) Somos 7110 surface before ABS overmoulding; (b) Huntsman 5260 surface before ABS overmoulding; (c) Somos 7110 surface after ABS overmoulding; (d) Huntsman 5260 surface after ABS overmoulding.

\section{$3.2 A B S$}

The results of the coefficient of friction with ABS mouldings showed trends similar to those with PP. The values had an increase until the 10th cycle, and remained approximately constant from thereon (figure 5).

Upon successive mouldings the SL block surfaces showed some scratching aligned with the friction test direction. This can result from the plastic deformation of the SL blocks during the friction test. The scratches were deeper in the Somos 7110 blocks than in the Vantico 5260 (figure 6). The Somos 7110 resin is less rigid than the Vantico 5260, which may explain the different surface behaviour (Westphal et al. 2006). For resins with the same tensile strength, those with higher ductility (or tenacity) can absorb more energy before plastic deformation. The roughness data acquired with this material are similar to the PP data.

\subsection{PET}

In the injection moulding of PET up to the 5th injection cycle, it was observed a strong adhesion of the moulded material to the SL resin blocks. In the figure 6 it is shown how the PET moulding was adhering to the resin block after moulding and before the friction test.

Table 2. Apparent roughness ( $\mathrm{Ra}$ ) and medium roughness (Rq) of Ren Shape 5260 e Somos 7110 block surfaces before and after overmoulding.

\begin{tabular}{lcc}
\hline Overmoulding & Somos $7110 \mathrm{Ra}-\mathrm{Rq}(\mu \mathrm{m})$ & Huntsman $5260 \mathrm{Ra}-\mathrm{Rq}(\mu \mathrm{m})$ \\
\hline Before & $0.36-0.45$ & $1.08-1.24$ \\
After PP & $0.66-0.79$ & $0.63-0.84$ \\
After ABS & $0.65-0.84$ & $0.59-0.73$ \\
After PET & $0.43-0.57$ & $0.49-0.61$ \\
After PA6.6 & $4.17-6.9$ & $1.71-2.12$ \\
\hline
\end{tabular}

The coefficient of friction of the pair 'Somos 7110/PET' up to then was of $0.60(\mathrm{Fa}=165 \mathrm{~N})$, and showed further increment up to $1.27(\mathrm{Fa}=349 \mathrm{~N})$ in the last mouldings (figure 7), representing an 8-fold increment with respect to the initials values. The coefficient of friction of the pair 'Vantico 5260/PET' after 5 mouldings was of $1.56(\mathrm{Fa}=$ $429 \mathrm{~N})$ and went on increasing up to 1.96, which corresponds to a friction force of $539 \mathrm{~N}$. In these tests no visuals effects were observed in the block surfaces, as shown in figure 7.

The roughness data corresponding to the Somos 7110 blocks did not show relevant difference before and after the experiments. Contrarily, the roughness data of the Vantico 5260 blocks decreased upon successive mouldings. The Ra

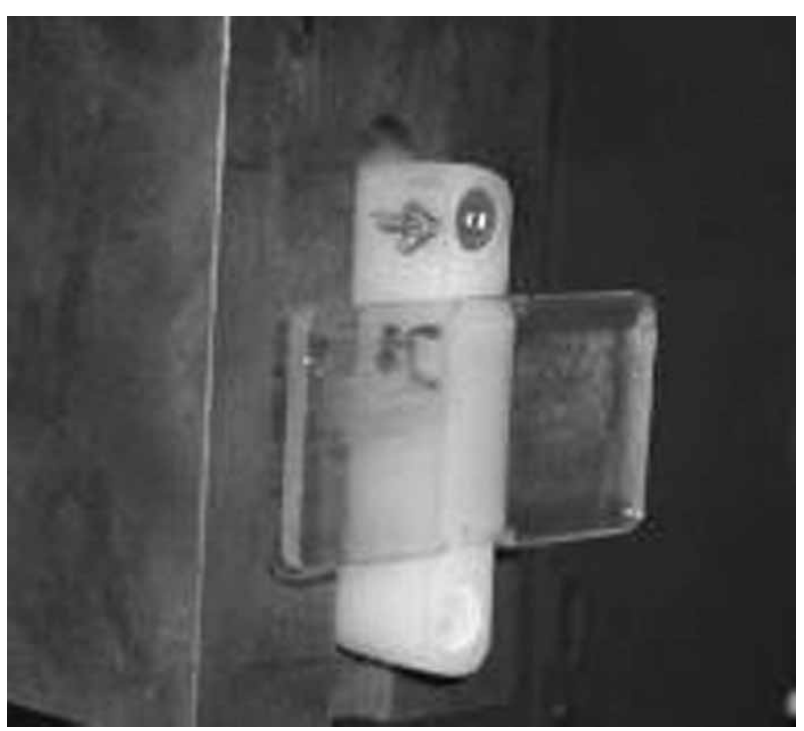

Figure 6. PET overmoulded onto a SL Huntsman 5260 block. 

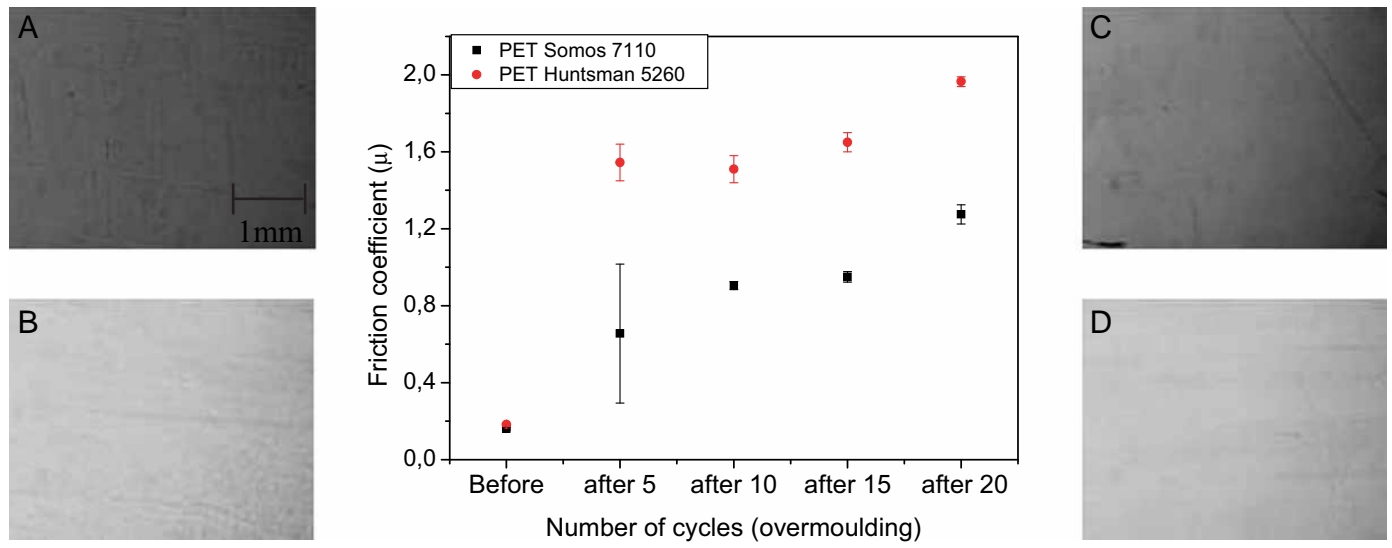

Figure 7. Coefficient of friction between SL blocks and PET: (a) Somos 7110 surface before PET overmoulding; (b) Huntsman 5260 surface before PET overmoulding; (d) Somos 7110 surface after PET overmoulding; (d) Huntsman 5260 surface after PET overmoulding.

values varied from 1.08 (before the experiments) to 0.48 (after the experiments), i.e. a decrease of $50 \%$.

The Vantico 5260 block surface topography, as measured with the laser MICROTOP equipment before moulding, shows the ridges caused by SL fabrication method (figure 8). The measurement of the same surfaces after the experiments showed the smoothing of the topography and a surface inclination: this evidences the plastic deformation suffered by the specimens during under injection moulding, and also the wear of the surface.

As the SL Somos 7110 blocks were not built by SL, their surface topography did not show the ridges characteristic of the SL fabrication method. Nevertheless features as the surface inclination after moulding was also observed, but being smaller than in the Huntsman 5260 blocks (figure 9).

\section{$3.4 P A 6.6$}

In the first mouldings of PA 6.6, it was observed that the mouldings also adhered to the block surfaces in both resins. During the experiments using the Somos 7110 blocks, the coefficient of friction (in the first mouldings) was of 0.6 , corresponding to a friction force of $165 \mathrm{~N}$. After the friction test, it was observed an intense wear of the block surface. This wear increased during subsequent cycles, but without strong adherence between the PA 6.6 and the SL resin. In the lasts moulding cycles, the SL resin block showed severe degradation of the surface (figure 10).

During the experiments using SL Vantico 5260 blocks, the coefficient of friction in the first cycle was of 2.0, corresponding to a friction force of $550 \mathrm{~N}$. As in the Somos 7110 experiments, it was observed a weak adherence between the moulded material and the block resin in this case after the second moulding. It was also observed the wear of the block surface, but less intensely than with the Somos 7110 resin. This difference of wear intensity during injection moulding was already reported elsewhere (Westphal et al. 2005) in moulds with moulding blocks built by SL using the same Somos 7110 and Vantico 5260 resins. This type of behaviour confirms the role of the chemical affinity between materials.

The roughness data of the Somos 7110 and Vantico 5260 blocks used with PA 6.6 were acquired at the less damaged regions as it was impossible at the more damaged areas.

\section{Discussion}

In the figure 11 the friction data for the SL Somos 7110 and Vantico 5260 resins and the moulded thermoplastics are plotted for better evaluation of the friction results.

The chemical affinity between the two SL resins and PET is clearly evidenced by the friction experiments. The first test data with PA 6.6 also suggest an adherence mechanism that may have been enhanced by the original asperities of the mouldings. The friction data for PET with both resins are superior to the PP and ABS data, as well as to the PA 6.6 values in the first injection cycles. This affinity between PET and the SL resins is confirmed by the friction data and the surface topography observations, where it is evident that the roughness diminishes while the friction force increases. The affinity between PA 6.6 and the SL resins is even more enhanced by the SL resin fragments still adherent to the PA 6.6 mouldings after moulding and friction testing.

It was observed that the SL Somos 7110 resin blocks are more damageable than the Vantico 5260. However the higher adhesive force was observed between the Vantico 5260 blocks and PET and PA 6.6. The elastic modulus of the SL Vantico 5260 resin being lower than SL Somos 7110 resin in spite of both having the same tensile strength 

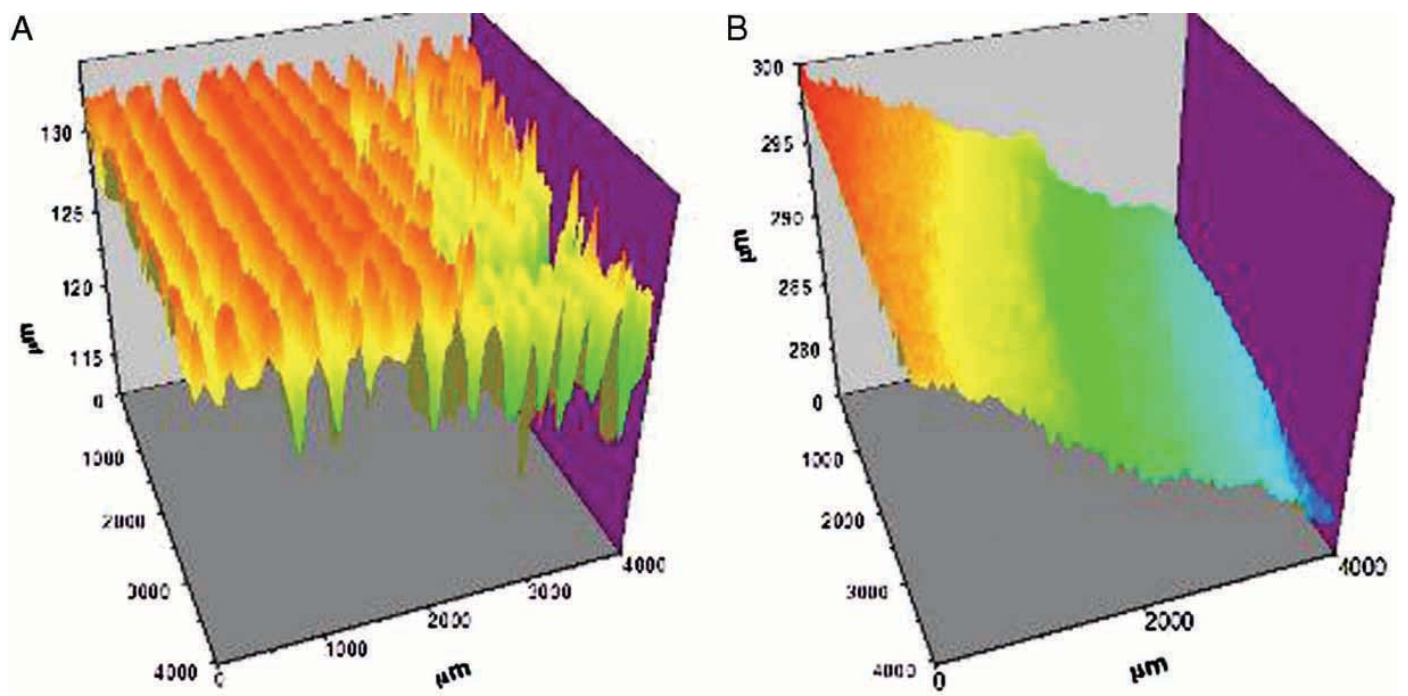

Figure 8. Surface topography of a SL Huntsman 5260 block. (a) before PET overmoulding; (b) after PET overmoulding.

(Westphal et al. 2004) suggests the possibility of the energy absorption before the fracture being higher with the less stiff Huntsman 5260 resin that consequently will be less prone to damage because of the higher ductility.

The static coefficient of friction between the SL blocks and the mouldings results not only from the roughness replication, but also from the adhesion between the SL block and the thermoplastic. The latter effect is more important in the cases where chemical bonding and diffusion of the molten thermoplastic into the SL block occurs. The degree of diffusion depends on the chemical affinity (or miscibility) between the materials, which can be estimated from the Hildebrand solubility parameter. This parameter that establishes a relationship with the polarity of the molecules can be related to the chemical affinity of the materials. Generally, polymers with the same solubility parameter, and consequently the same cohesive energy density, tend to be miscible with each other or to show adhesive characteristics (Petrie 2005).

The Hildebrand solubility parameter of epoxy resins derived from the bisphenol-A, is approximately of $22 \mathrm{MPa}^{1 / 2}$. PET and PA 6.6 have similar values for the solubility parameters $\left(21.54 \mathrm{MPa}^{1 / 2}\right.$ and $22.87 \mathrm{MPa}^{1 / 2}$ respectively). The values of this parameter for $\mathrm{PP}$ and ABS are respectively of $18.8 \mathrm{MPa}^{1 / 2}$ and $17.90 \mathrm{MPa}^{1 / 2}$ (Brandrup et al. 2005). Both resins have p-substituted aromatic groups and low glass transition temperatures, indicating a low crosslinking density, which makes easier the thermoplastic diffusion between the epoxyde network. Therefore the existence of chemical affinity between the SL resins (Somos 7110 and Vantico 5260) and the thermoplastics (PET and PA 6.6) can be suggested.
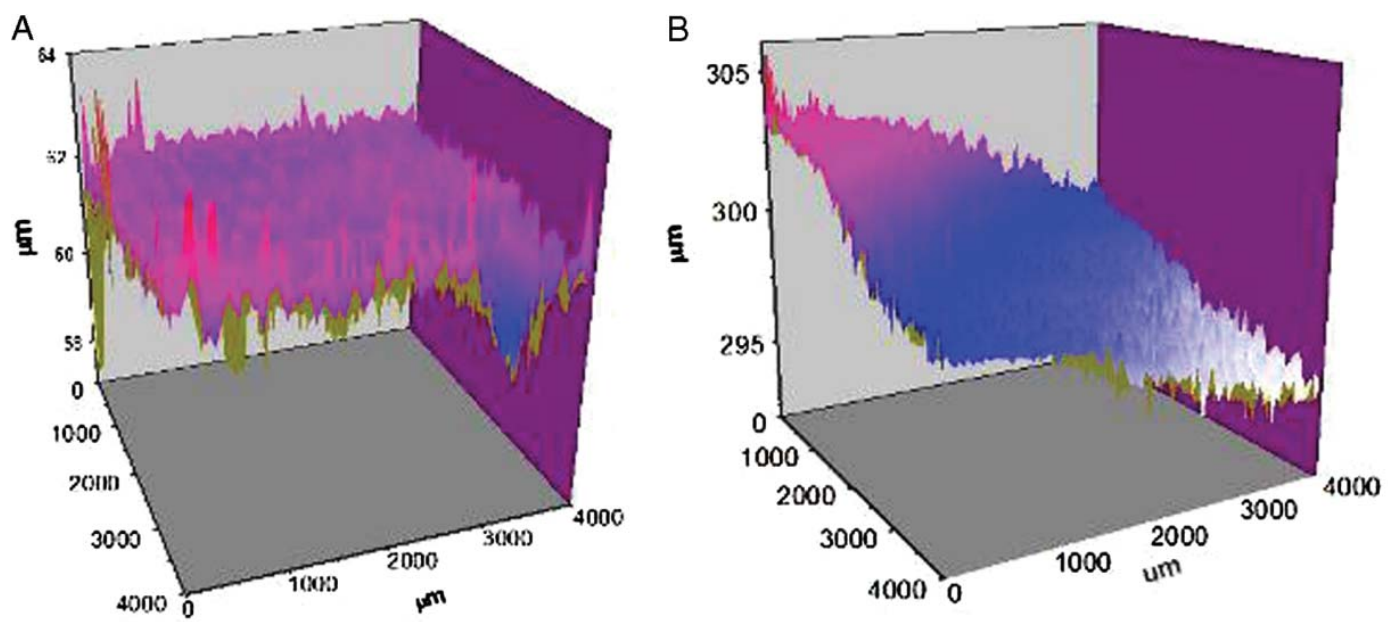

Figure 9. Surface topography of SL Huntsman 5260 blocks: (a) before PET overmoulding; (b) after PET overmoulding. 

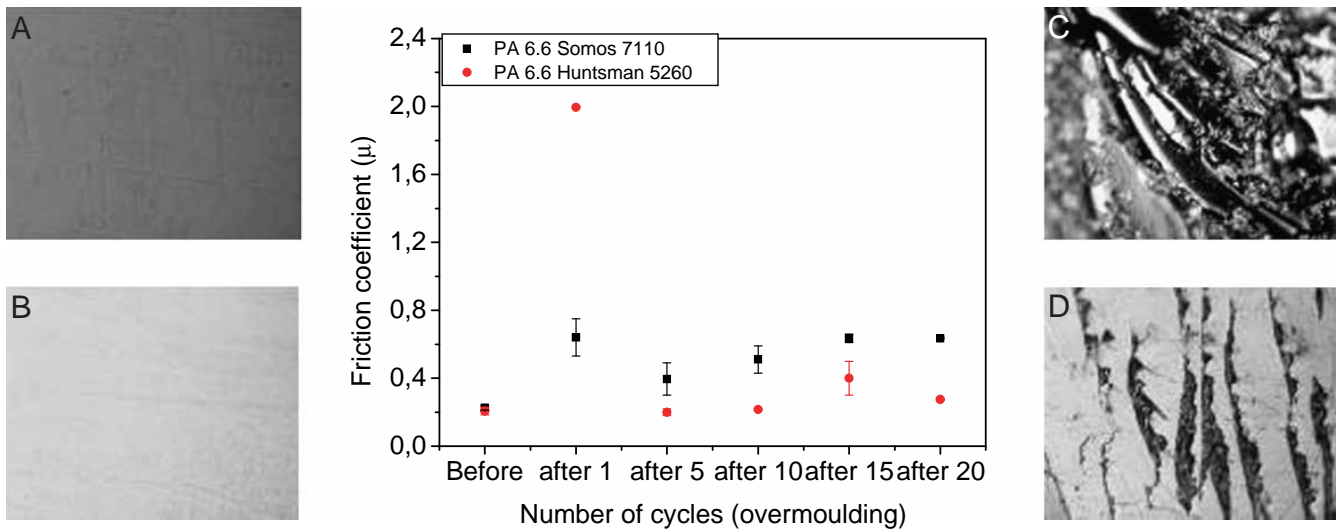

Figure 10. Coefficient of friction between SL blocks and PA 6.6: (a) Somos 7110 surface before PA 6.6 overmoulding; (b) Huntsman 5260 surface before PA 6.6 overmoulding; (c) Somos 7110 surface after PA 6.6 overmoulding; (d) Huntsman 5260 surface after PA 6.6 overmoulding.
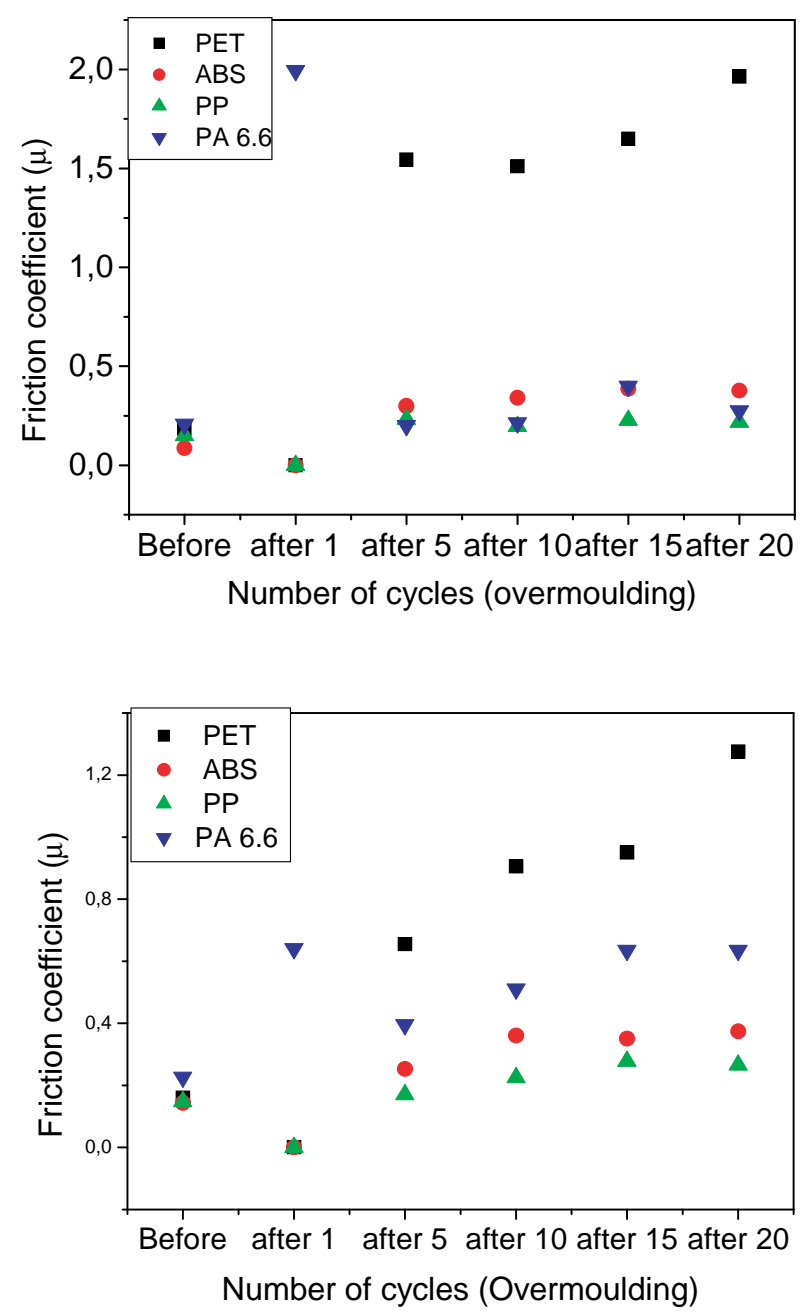

Figure 11. Friction data for SL Vantico 5260 and Somos 7110 blocks.

\section{Conclusions}

Hybrid moulds can be manufactured using polymeric based moulding blocks (core and cavity). When stereolithography (SL) is used for producing these blocks for moulds for injection moulding, the knowledge of the mechanical and chemical characteristics of the SL resin is important for guaranteeing the success of the mould performance, especially when resins with low crosslinking density are used.

The use of Hildebrand solubility parameter tables help to choose the best resin for a SL moulding block if the thermoplastics to be injected is known in advance. The choice of the best SL resin for the moulding blocks of a rapid tool, leads preferentially to a resin with high tensile strength and $T_{\mathrm{g}}$ transition temperature, but with a intermediate elastic modulus, in order to make possible more energy being absorbed before tool fracture.

The adhesion between the SL resin for the moulding block and the material to be moulded can be assessed by a friction test made with samples overmoulded in testing blocks sterolithographed in the material similar to that used in the injection mould. This test informs not only on the effective friction properties but also on the likelihood of chemical adhesion between the thermoplastics and the SL resin.

\section{Acknowledgements}

The authors thank the EU Programme ALFA for granting M. W. Gonçalves a mobility grant to University of Minho under the project Plastinet-master.

\section{References}

Brandrup, J., Immergut, E. H. and Grulke, E. A., Polymer handbook (4th edition), 1999 (John Wiley: New York). 
Cedorege, T., Le Baut, Y., Palmer, A. and Colton, J., Design rules for stereolithography injection molding inserts. Proceedings of the 8th European Conference on Rapid Prototyping in Manufacturing, 1999, Nottingham.

Colton, J. S. and Lebaut, Y., Thermal effects on stereolithography Injection mold inserts, Polymer Engineering and Science., 2000, 40, 1360-1368.

Costa, M. F., Surface inspection by an optical triangulation method, Opt. Engng, 1996, 35, 2743-2747.

Ferreira, E. C., Muschalle, R., Neves, N. M. and Pouzada, A. S., Analysis of parameters determining the friction properties of thermoplastics in injection moulding. In Proceedings of ANTEC 2002 Conference, 2002, San Francisco.

Fourche, G., An overview of the basic aspects of polymer adhesion, Part I: Fundamentals, Polym, Engng Sci., 1995, 35, 957-967.

Fourche, G., An overview of the basic aspects of polymer adhesion, Part II: Application to surface treatments, Polym, Engng Sci., 1995, 35, 968-974.

ASTM G-40-99, Standard tesminology relating to wear and erosion. Annual Book of Standards. 2000, 03.02, 158-165.

Hopkinson, N. and Dickens, P. M., Study of ejection forces in the AIM ${ }^{\mathrm{TM}}$ process. Mater. Des. 1999, 20, 99-105.

Jacobs, P. F., Stereolithography and Other RP\&M Technologies, 1996 (RPA/ ASME: New York).

Lavielle, L., Polymer-polymer friction: Relation to adhesion, Wear, 1991, 151, 63-75.
Menges, G., Measurement of coefficient of static friction as a means of determining opening and demoulding forces in injection moulds, Kunststoffe, 1981, 71, 552-557.

Palmer, A. E. and Colton, J. S., Failure mechanisms in stereolithography injection molding tooling, Polym, Engng Sci., 2000, 40, 1395-1404.

Petrie, E. M., Handbook of Adhesives and Sealants, 2000 (McGraw-Hill: New York).

Pouzada, A. S., Ferreira, E. C. and Pontes, A. J., Friction properties on moulding thermoplastics, Polymer Testing, 2006, 25, 1017-1023.

Ribeiro Jr., A. R., Hopkinson, N. and Ahrens, C. H., Thermal effects on stereolithography tools during injection moulding, Rapid Prototyping J., 2004, 10, 176-180.

Salmoria, G. V., Gonzalez, V. J., Ahrens, C. H., Soldi, V. and Pires, A. T. N., Stereolithography Somos 7110 photosensitive resin: study of curing kinetic and thermal degradation, J. Materials Process, Technol, 2005, 168, $164-171$.

Westphal, M. G., Pouzada, A. S., Salmoria, G. V. and Ahrens, C. H., Performance and friction properties of injection hybrid moulds with SL moulding zones. Mater. Sci. Forum, 2006, 514-516, 1673-1675.

Westphal, M. G, Salmoria, G. V. and Ahrens, C. H., Determination of mechanical behavior of stereolithography resins used in rapid tool for injection moulding. In Proceedings of PPS 2004 Conference, 2004, Florianópolis. 